\title{
Detection of Structural Abnormalities and Ultrasonic Soft Markers in the First Trimester Screening
}

\author{
J. W. WANG, L. Y. GUO, L. CHEN, C. YAO AND B. LAI* \\ Department of Gastrointestinal Surgery, The Second Affiliated Hospital of Nanchang University, No. 1, Minde Road, Nanchang \\ of Jiangxi, 330006, China
}

Wang et al.: Detection of structural abnormalities in the first trimester screening

\begin{abstract}
The aim of this study was to explore the application of standardized ultrasonography in the first trimester. A total of 1670 pregnant women who underwent ultrasonography in the first trimester (1706 fetuses) and 2,562 pregnant women who underwent ultrasonography in the second trimester (2637 fetuses) visiting the Second Affiliated Hospital of Nanchang University from January 2016 to December 2018 were included in this prospective study. Standardized ultrasonography was performed on the fetuses and pregnancy outcomes were tracked in abnormal cases. A total of 20 cases of fetal structural abnormalities were detected in the first trimester and the number of pregnant women who chose to induce labor was as high as 15. A total of 41 cases of fetal soft marker abnormalities were detected in the first trimester and most of these markers returned to normal. A total of 113 cases of malformed fetuses were detected in the second trimester. Additionally, those cases that did not undergo standardized ultrasonography in the first trimester were significantly more likely to show fetal abnormalities in the second trimester than those who had standardized ultrasonography in the first trimester. Some fetal malformations, especially some severe ones, can be detected by standardized ultrasonography in the first trimester. However, standardized ultrasonography in the second trimester which was regard as the best period for fetal malformation detection cannot be replaced by the first trimester. It is better to conduct standardized ultrasonography in both first and second trimesters.
\end{abstract}

Key words: Ultrasonography, structural abnormalities, pregnant women, fetus

Birth defects are the abnormal developmental changes that occur in the maternal uterus before the baby is born. The status quo of birth defects in China not only is a serious public health problem but also has become a social problem that affects economic development and people's daily lives. To solve this problem, medical research continues to prevent the emergence of birth defects. There are some effective ways to reduce the incidence of birth defects in infants, such as, reduce the risk factors that lead to birth defects and improve the rate of early diagnosis of fetal malformations during pregnancy ${ }^{[1,2]}$.

Ultrasonography as a means of prenatal diagnosis plays a very important role in detecting fetal malformation and involved in saving the fetus ${ }^{[3]}$. At present, systematic standardized ultrasonography of the fetus is generally performed in second trimester (between 18 and $22 \mathrm{w}$ of gestation). However, with the rapid development of ultrasound imaging technology and the use of high-resolution ultrasound instruments, standardized ultrasonography in the first trimester (11-14 w of gestation) has been to be effective. Standardized ultrasonography of the fetus in the first trimester can detect some serious fetal malformations, avoiding the induction of labor during the advanced gestational age, thus effectively reducing the psychological and physical toll on pregnant women $^{[4,5]}$. Therefore, the development of standardized ultrasonography of fetus in the first trimester has been receiving increased attention. Experts point out that standardized ultrasonography should not only be conducted in the second trimester but also in the first trimester ${ }^{[6]}$.

Prenatal standardized ultrasonography in the first trimester can not only detect obvious fetal structural abnormalities but also can identify some clinically unclear features that are considered to be possible markers of aneuploidy. These markers are collectively 
referred to as ultrasonic soft markers ${ }^{[7]}$. These ultrasonic soft markers reported in the first trimester include increased nuchal translucency (NT), nasal bone absence, choroidal cyst, single umbilical artery and so on. Although an abnormality of the ultrasonic soft markers of the fetus does not equal fetal abnormality, a large number of studies have found that there is a certain correlation between abnormal fetal soft markers and chromosomal abnormalities or structural abnormalities. Therefore, this study analysed the data regarding abnormalities of fetal structure and ultrasonic soft markers in the first trimester in the Second Affiliated Hospital of Nanchang University from January 2016 to December 2018. Moreover, the detection of fetal structural abnormality in the second trimester was compared to pregnant women who have undergone standardized ultrasonography in the first trimester and those who did not. With these methods, the significance of standardized ultrasonography of the fetus in the first trimester could be discussed.

\section{MATERIALS AND METHODS}

\section{Subject selection:}

A total of 1670 pregnant women whose gestation is between 11 and $14 \mathrm{w}$ (1634 singles, 36 twins, total 1706 fetuses) and 2562 pregnant women whose gestation is between 18 and $22 \mathrm{w}$ ( 2487 singles, 75 twins, total 2637 fetuses) visiting the Second Affiliated Hospital of Nanchang University hospital from January 2016 to December 2018 were included in this prospective study. Standardized ultrasonography was performed on the pregnant women and pregnancy outcomes were tracked in abnormal cases.

\section{Ultrasound screening instrument and method:}

Philips IU22 and GE Voluson E8 Color Doppler Ultrasound Diagnostics were used for this study. The probe frequencies were 3.5 to 6.0 and 4.0 to $6.0 \mathrm{MHz}$, respectively. The examiner was a physician with more than $3 \mathrm{y}$ of clinical ultrasound training who has passed the fetal ultrasonography examination. A fetus detected with suspected malformation or abnormal ultrasonic soft markers was further examined by a senior physician. The standardized ultrasonography in the first trimester included, measurement of crownrump length (CRL), NT, ductusvenosus (DV) doppler waveform, depth of amniotic fluid, placental thickness and doppler assessment of umbilical artery. Continuous scanning of fetal brain, face, chest, heart, abdomen, spine and limbs. Standardized ultrasonic views were

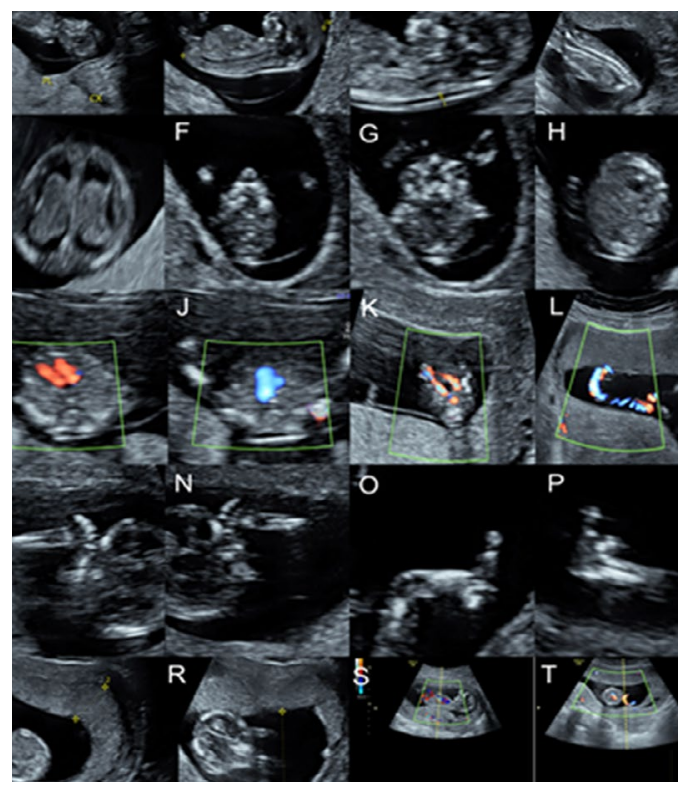

Fig. 1: Standardized ultrasonic views in the first trimester A. Longitudinal view of maternal cervix; B. Crown-rump length (CRL) measurement view; $C$. Nuchal translucency (NT) measurement view; D. Sagittal view of the spine; E. Transverse view of the skull; F. Retro nasal triangle view; G. Transverse view through eyes. H. Transverse view through stomach; I. Four-chamber view; J. Threevessel view; $K$. The view of umbilical cord insertion in the fetal abdomen; $L$. The view of umbilical cord attachment in the placenta; MN. Bilateral upper limb views; OP. Bilateral lower limb views; $Q$. Measurement of the placental thickness; R. Measurement of the deepest amniotic fluid; $S$. Doppler assessment of ductus venosus (DV); T. Doppler assessment of umbilical artery

stored (fig. 1). The standardized ultrasonography in second trimester was 32-39 standard views according to guidelines and experts ${ }^{[8-11]}$.

\section{Non-invasive DNA testing:}

For pregnant women who volunteered for non-invasive genetic testing, venous blood was taken between 12 and $24 \mathrm{w}$ of gestation and sent to the testing centre to assess the risk of fetal chromosomal abnormalities.

\section{Karyotype analysis of amniotic fluid or umbilical cord blood puncture:}

Pregnant women, who had the necessity and agreed to undergo karyotype analysis after a comprehensive assessment, amniotic fluid or umbilical cord blood was drawn and send to the testing centre for karyotype analysis.

\section{Ultrasonic detection results of the fetal structural abnormalities in the first trimester:}

A total of 1706 fetuses were examined in the first 
trimester and 20 cases of fetal structural abnormalities were detected (Table 1, fig. 2). Seven cases of severe neural tube defects were detected, including acrania, holoprosencephaly, encephalocele, and spina bifida; 3 cases of obvious cardiac malformations were detected, including single atrium, single ventricle and endocardial cushion defect; and 4 cases of obvious limb malformations were detected, including arthrogryposis multiplex congenita, abnormal hand and foot postures, foot deficiency, and clubfoot. There were three cases combined with soft marker abnormalities in these 20 cases of fetal structural abnormalities, including increased NT, choroidal cyst, and single umbilical artery. And also, there were five cases with chromosomal abnormalities. Since most of fetal malformations in these 20 cases were severe or the karyotype analysis was abnormal, the number of pregnant women who chose abortion was as high as 15 .

\section{The ultrasonic detection results of the fetal soft marker abnormalities in the first trimester:}

In the first trimester, 41 cases of abnormal fetal soft markers were detected (Table 2, fig. 3), including 22 cases of increased NT, 4 cases of choroidal cyst, 5 cases of single umbilical artery, 3 cases of nasal bone absence, 1 case of increased NT with abnormal DV doppler waveform, 1 case of increased NT with nasal bone absence, 1 case of increased NT with choroidal cyst, and 1 case of nasal bone absence with abnormal DV doppler waveform. Then, we conducted a DNA or karyotype test or follow-up. The results showed that there were 30 cases of normal labour (meant no deformation after birth), 6 cases of fetal karyotype abnormalities or fetal structural abnormalities, and 5 cases lost to follow-up.

\section{The ultrasonic detection results of fetal structural abnormalities in the second trimester}

A total of 2637 fetuses were examined in the second trimester, of which 1363 fetuses had undergone standardized ultrasonography in the first trimester and 1274 fetuses underwent standardized ultrasonography in the second trimester. A total of 113 cases of malformed fetuses were detected (Table 3, fig. 4), and those which did not undergo standardized ultrasonography in the first trimester were significantly more likely to have fetal abnormalities in the second trimester than those who underwent standardized ultrasonography in the first trimester (76 vs 37 cases). Moreover, compared to the fetuses that had standardized ultrasonography in the first trimester, the fetuses that did not have standardized ultrasonography in the first trimester had more types of

TABLE 1: ULTRASONIC DETECTION RESULTS OF THE FETAL STRUCTURAL ABNORMALITIES IN THE FIRST TRIMESTER

\begin{tabular}{|c|c|c|c|c|}
\hline Age (y) & Ultrasonic structural abnormality & Ultrasonic soft markers abnormality & Karyotype & Follow-up results \\
\hline 35 & Holoprosencephaly & Increased NT & $47, \mathrm{XN},+13$ & abortion \\
\hline 39 & Holoprosencephaly+Nuchal Cystic Hygroma & / & $46, \mathrm{XN}$ & abortion \\
\hline 32 & Encephalocele+Polycystic kidneys & / & $46, \mathrm{XN}$ & abortion \\
\hline 29 & Encephalocele & / & $46, \mathrm{XN}$ & abortion \\
\hline 32 & Acrania+Abnormal Posture of Hands and Feet & / & Undetected & abortion \\
\hline 26 & Spina Bifida & / & $46, \mathrm{XN}$ & abortion \\
\hline 24 & Endocardial Cushion Defect & / & $46, \mathrm{XN}$ & abortion \\
\hline 35 & Exomphalos & / & Undetected & loss to follow-up \\
\hline 34 & Giant Bladder & / & $46, \mathrm{XN}$ & abortion \\
\hline 37 & Arthrogryposis Multiplex Congenita & / & $47, \mathrm{XN},+18$ & abortion \\
\hline 25 & Single Atrium, Single Ventricle+Clubfoot & / & $46, \mathrm{XN}$ & abortion \\
\hline 32 & Body Stalk Anomaly & / & $47, \mathrm{XN},+18$ & abortion \\
\hline 26 & Nuchal Cystic Hygroma & Single umbilical artery & $47, \mathrm{XN},+21$ & abortion \\
\hline 31 & Nuchal Cystic Hygroma & / & $46, \mathrm{XN}$ & loss to follow-up \\
\hline 28 & Nuchal Cystic Hygroma+Hydrops Fetalis & / & Undetected & abortion \\
\hline 28 & Nuchal Cystic Hygroma+Hydrops Fetalis & / & $46, \mathrm{XN}$ & Fetal reduction \\
\hline 31 & $\begin{array}{l}\text { Nuchal Cystic Hygroma+Hydrops } \\
\text { Fetalis+Exomphalos }\end{array}$ & / & $47, \mathrm{XN},+21$ & abortion \\
\hline 22 & $\begin{array}{c}\text { Spina Bifida, Cleft Lip and Cleft Palate (one of } \\
\text { the twins) }\end{array}$ & / & $46, X N$ & Fetal reduction \\
\hline 29 & $\begin{array}{c}\text { Cleft Lip and Cleft Palate, Right Foot } \\
\text { Deficiency }\end{array}$ & Choroidal cyst & $46, X N$ & abortion \\
\hline 28 & $\begin{array}{c}\text { Single Atrium, Single Ventricle, } \\
\text { Nuchal Cystic Hygroma }\end{array}$ & / & Undetected & abortion \\
\hline
\end{tabular}


fetal malformations, especially some serious ones like encephalocele, open spina bifida and gastroschisis and so on.

\section{RESULTS AND DISCUSSION}

Fetal malformation affects not only the growth and development of the fetus but also the safety of infants and young children and imparts a serious burden to families and society. Ultrasonography plays an important role in prenatal screening and diagnosis because of its safety, simplicity, non-invasiveness and real-time measurements. At present, systematic standardized ultrasonography of the fetus is generally performed in the second trimester (between 18 and

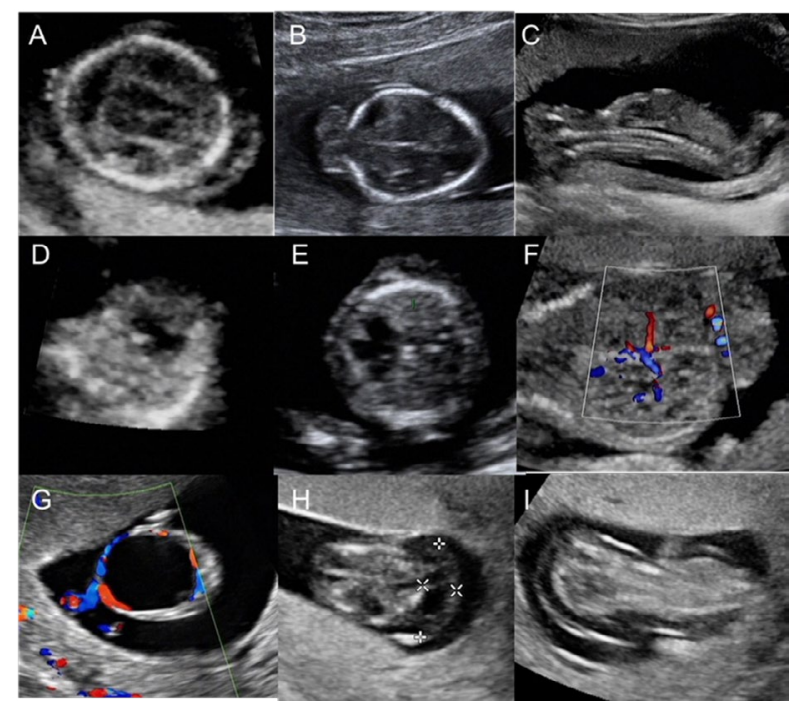

Fig. 2: Images of fetal structural abnormalities in the first trimester

A. Holoprosencephaly; B. Encephalocele; C. Acrania; D. Single atrium, single ventricle; E. Endocardial cushion defect; F. Polycystic kidneys; G. Giant bladder; H. Nuchal cystic hygroma; I. Hydrops fetalis
$22 \mathrm{w}$ of gestation $)^{[12-14]}$. However, with the rapid development of ultrasound imaging technology and the use of high-resolution ultrasound instruments in recent years, fetal standardized ultrasonography in the first trimester has become possible and has attracted greater attention. Some experts have pointed out that standardized ultrasonography should not only be conducted in the second trimester but also in the first trimester. The standardized ultrasonography in the first trimester screening not only can detect severe fetal structural abnormalities but also can play a role in alerting the physician and patient of fetal chromosomal abnormalities through ultrasonic soft markers.

At first, our results demonstrated that standardized ultrasonography in the first trimester can detect a lot

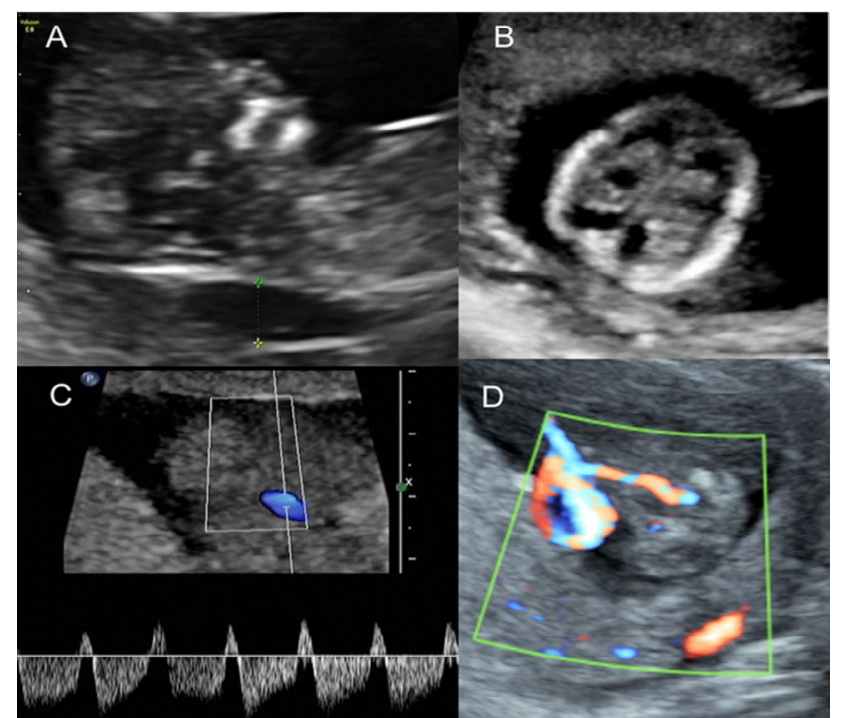

Fig. 3: Images of ultrasonic soft markers in the first trimester

A. Increased NT; B. Choroidal cyst; C. Reversed a-wave in the ductus venosus Doppler flow; D. Single umbilical artery

TABLE 2: THE ULTRASONIC DETECTION RESULTS OF THE FETAL SOFT MARKER ABNORMALITIES IN THE FIRST TRIMESTER

\begin{tabular}{|c|c|c|c|c|}
\hline \multicolumn{2}{|l|}{ Abnormal ultrasonic soft marker in the first trimester } & \multicolumn{3}{|c|}{ The tracking results of the mid-trimester } \\
\hline class & $\begin{array}{l}\text { Number of } \\
\text { cases }\end{array}$ & Normal & Abnormal & Lost \\
\hline Increased NT & 22 & 16 & $\begin{array}{c}3 \text { ( } 2 \text { cases } 21 \text {-trisomy, } 1 \text { case of fetal } \\
\text { heart malformation) }\end{array}$ & 3 \\
\hline Choroidal cyst & 4 & 4 & l & / \\
\hline Single umbilical artery & 5 & 4 & / & 1 \\
\hline Nasal bone absence & 3 & 2 & 1 (21-trisomy) & / \\
\hline Abnormal DV Doppler waveforms & 3 & 2 & 1case (fetal heart malformation) & / \\
\hline Increased NT and abnormal DV Doppler waveforms & 1 & 1 & l & / \\
\hline Increased NT and nasal bone absence & 1 & / & 1case (21-trisomy) & / \\
\hline Increased NT with choroidal cyst & 1 & 1 & I & I \\
\hline $\begin{array}{l}\text { Nasal bone absence and abnormal DV Doppler } \\
\text { waveforms }\end{array}$ & 1 & I & I & 1 \\
\hline Total number of cases & 41 & 30 & 6 & 5 \\
\hline
\end{tabular}


TABLE 3: THE ULTRASONIC DETECTION RESULTS OF FETAL STRUCTURAL ABNORMALITIES IN THE SECOND TRIMESTER

\begin{tabular}{|c|c|c|c|c|c|}
\hline \multicolumn{2}{|c|}{ Structural Malformation } & \multicolumn{2}{|c|}{$\begin{array}{l}\text { Standardized ultrasonography in the } \\
\text { first trimester }\end{array}$} & \multicolumn{2}{|c|}{$\begin{array}{l}\text { No standardized ultrasonography in the first } \\
\text { trimester }\end{array}$} \\
\hline Class & $\begin{array}{l}\text { Nor of } \\
\text { cases }\end{array}$ & $\begin{array}{l}\text { No of } \\
\text { cases }\end{array}$ & diseases & $\begin{array}{l}\text { No of } \\
\text { cases }\end{array}$ & diseases \\
\hline Brain & 21 & 6 & $\begin{array}{l}\text { Hydrocephalus, Blake } \\
\text { porch cyst, corpus callosum } \\
\text { agenesis, cerebellar dysplasia }\end{array}$ & 15 & $\begin{array}{l}\text { Encephalocele, schizencephaly, corpus } \\
\text { callosum agenesis, hydrocephalus, } \\
\text { cerebellar hypoplasia, acrania }\end{array}$ \\
\hline Face & 12 & 4 & Cleft lip, cleft palate & 8 & $\begin{array}{l}\text { Cleft lip, cleft palate, abnormal ear } \\
\text { morphology }\end{array}$ \\
\hline Spine & 10 & 3 & $\begin{array}{l}\text { Hemivertebra, closed spina } \\
\text { bifida }\end{array}$ & 7 & $\begin{array}{l}\text { Butterfly vertebra, hemivertebra, open } \\
\text { spina bifida, fused vertebra }\end{array}$ \\
\hline Cardiovascular & 20 & 7 & $\begin{array}{l}\text { Ventricular septal defect, } \\
\text { endocardial cushion defects, } \\
\text { cardiomyopathy, tetralogy of } \\
\text { Fallot, hypoplastic left heart } \\
\text { syndrome. }\end{array}$ & 13 & $\begin{array}{l}\text { Single ventricle, absent pulmonary valve, } \\
\text { ventricular septal defect, endocardial } \\
\text { cushion defect, hypoplastic left heart } \\
\text { syndrome, cardiomyopathy, Ebstein's } \\
\text { anomaly, transposition of the great } \\
\text { arteries, tetralogy of Fallot. }\end{array}$ \\
\hline Chest & 14 & 6 & $\begin{array}{l}\text { Congenital cystic adenomatoid } \\
\text { malformation, pulmonary } \\
\text { sequestration }\end{array}$ & 8 & $\begin{array}{c}\text { Congenital cystic adenomatoid } \\
\text { malformation, pulmonary sequestration, } \\
\text { high airway obstruction, diaphragmatic } \\
\text { hernia }\end{array}$ \\
\hline Abdomen & 18 & 6 & $\begin{array}{l}\text { Polycystic kidney, } \\
\text { hydronephrosis, ectopic } \\
\text { kidney }\end{array}$ & 12 & $\begin{array}{l}\text { Exomphalos, gastroschisis, duodenal } \\
\text { atresia polycystic kidney, hydronephrosis, } \\
\text { ectopic kidney }\end{array}$ \\
\hline Limb & 10 & 3 & clubfoot, short limbs & 7 & $\begin{array}{l}\text { Clubfoot, arthrogryposis multiplex } \\
\text { congenita, foot deficiency, short limbs }\end{array}$ \\
\hline Others & 8 & 2 & $\begin{array}{l}\text { Lymphangioma, hydrops } \\
\text { fetalis }\end{array}$ & 6 & Hydrops fetalis, multiple abnormality \\
\hline Total number of cases & 113 & 37 & & 76 & \\
\hline
\end{tabular}

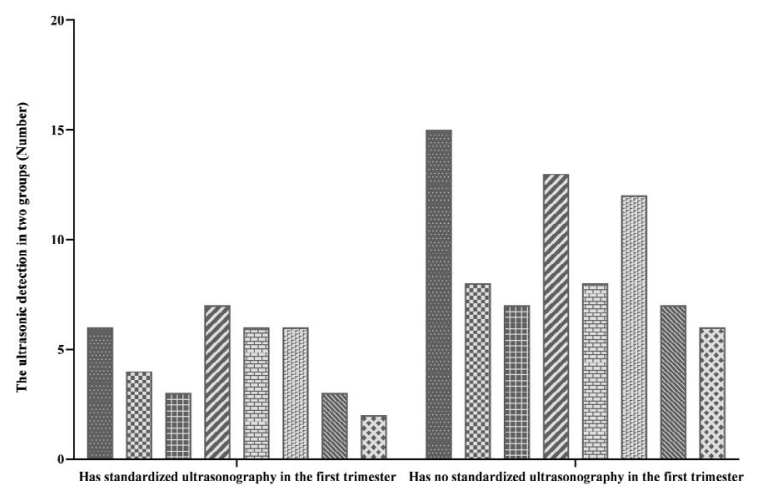

Fig. 4: Ultrasonic detection in two groups

A total of 113 cases of malformed fetuses were detected, and those that did not undergo standardized ultrasonography in the first trimester were significantly more likely to have fetal abnormalities in the second trimester than those who underwent standardized ultrasonography in the first trimester ( 76 vs 37 cases)

of fetal malformations, especially for some serious ones. A total of 1686 fetuses were examined in the first trimester in our study and 20 cases of fetal structural malformations were detected. And also, most of these were severe abnormality or complicated with karyotype abnormalities. Therefore, up to 15 pregnant women were selected for abortion. Therefore it is necessary to promote the use of standardized ultrasonography in the first trimester.

Secondly, our results showed that a lot of abnormal soft markers could be detected by standardized ultrasonography in the first trimester. Fetal ultrasonic soft markers have become a research hot spot in recent years, including nasal bone absence, mild ventriculomegaly, mild renal pyelectasis, choroidal cyst, single umbilical artery, echogenic intracardiac focus and so on. Although abnormal ultrasonic soft markers are not equal to fetal abnormalities, a large number of studies have found a certain correlation between abnormal ultrasonic soft markers and chromosomal abnormalities or structural abnormalities $^{[15,16]}$. In this study, a total of 41 cases of fetal soft marker abnormalities were detected in the first trimester. In the later follow-up, it was found that most of them returned to normal and some had karyotype abnormalities or fetal structural abnormalities. Therefore, the recommendation is that if ultrasonic soft markers are found in the first trimester, doctors should be optimistically communicate with pregnant women and their families, but at the same time, doctors should inform them of the risk of fetal chromosomal 
abnormalities or structural abnormalities.Last but not the least, compared to the fetuses that had standardized ultrasonography in the first trimester, the fetuses that did not have standardized ultrasonography in the first trimester were significantly more likely to show fetal abnormalities in the second trimester ( 76 vs 37 cases). Moreover, they had more types of fetal malformations, especially for some serious ones, like encephalocele, open spina bifida, and gastroschisis and so on. These results further indicated that it is very important to conduct standardized ultrasonography in the first trimester and that the standardized ultrasonography in the second trimester could not be replaced by the standardized ultrasonography in the first trimester.

\section{CONCLUSION}

In general, the application of standardized ultrasonography in the first trimester is of great significance. On the one hand, it can detect some severe structural abnormalities at an early stage, avoiding the abortion of the fetus in the middle and third trimester, thus effectively reducing the psychological and physical toll on pregnant women. On the other hand, some fetal soft marker abnormalities can be found, which can help guide clinical chromosomal examination and followup, thereby reducing the birth defect rate. However, since fetal structure develops in a continuous and dynamic process, some fetal malformations are difficult to observe in the first trimester; therefore it is necessary to also conduct standardized ultrasonography in second trimester.

\section{Conflict of interest:}

All authors report no conflicts of interest in this work.

\section{REFERENCES}

1. Weedn AE, Mosley BS, Cleves MA, Waller DK, Canfield MA, Correa A, et al. Maternal reporting of prenatal ultrasounds among women in the National Birth Defects Prevention Study. ClinMolTeratol 2014;100: 4-12.

2. Ailes EC, Gilboa SM, Riehle-Colarusso T, Johnson CY, Hobbs CA, Correa A, et al. Prenatal diagnosis of nonsyndromic congenital heart defects. PrenatDiagn 2014;34:214-22.

3. Audibert F, Gagnon A, Wilson RD, Blight C, Brock JA, Cartier $\mathrm{L}$, et al. Prenatal screening for and diagnosis of aneuploidy in twin pregnancies. J ObstetGynaecol Can 2011;33:754-67.

4. Timor-Tritsch IE, Bashiri A, Monteagudo A, Arslan AA. Qualified and trained sonographers in the US can perform early fetal anatomy scans between 11 and 14 weeks. Am J ObstetGynecol 2004;191:1247-52.
5. Timor-Tritsch IE, Bashiri A, Monteagudo A, Rebarber A, Arslan AA. Two hundred ninety consecutive cases of multifetal pregnancy reduction: comparison of the transabdominal versus the transvaginal approach. Am J ObstetGynecol 2004;191:2085-9.

6. Nicolaides KH. A model for a new pyramid of prenatal care based on the 11 to 13 weeks assessment. PrenatDiagn 2011;31:3-6.

7. Karadzov-Orlic N, Egic A, Filimonovic D, Damnjanovic-Pazin $\mathrm{B}$, Milovanovic Z, Lukic R, et al. Screening performances of abnormal first-trimester ductusvenosus blood flow and increased nuchal translucency thickness in detection of major heart defects. PrenatDiagn 2015;35:1308-15.

8. Nicolaides KH, Heath V, Liao AW. The 11-14 week scan. Baillieres Best Pract Res ClinObstetGynaecol 2000;14:58194.

9. Salomon LJ, Alfirevic Z, Berghella V, Bilardo C, HernandezAndrade E, Johnsen SL, et al. Practice guidelines for performance of the routine mid-trimester fetal ultrasound scan. Ultrasound ObstetGynecol 2011;37:116-26.

10. Leung KY, Poon CF, Teotico AR, Hata T, Won HS, Chen M, et al. Recommendations on routine mid-trimester anomaly scan. J ObstetGynaecol Res 2015;41:653-61.

11. Perovic M, Gojnic M, Arsic B, Pantic I, Stefanovic T, Kovacevic $\mathrm{G}$, et al. Relationship between mid-trimester ultrasound fetal liver length measurements and gestational diabetes mellitus. J Diabetes 2015;7:497-505.

12. Chauveau B, Auclair C, Legrand A, Mangione R, Gerbaud $\mathrm{L}$, Vendittelli $\mathrm{F}$, et al. Improving image quality of midtrimester fetal sonography in obese women: role of ultrasound propagation velocity. Ultrasound ObstetGynecol 2018;52:769775.

13. Kapoor S, Thomas JT, Petersen SG, Gardener GJ. Is the third trimester repeat ultrasound scan for placental localisation needed if the placenta is low lying but clears of the os at the mid-trimester morphology scan? Aust N Z J ObstetGynaecol 2014;54:428-32.

14. Srisupundit K, Tongsong T, Sirichotiyakul S, Chanprapaph P. Fetal structural anomaly screening at 11-14 weeks of gestation at MaharajNakorn Chiang Mai Hospital. J Med Assoc Thai 2006;89:588-93.

15. Cedergren $M$, Selbing A. Detection of fetal structural abnormalities by an 11-14-week ultrasound dating scan in an unselected Swedish population. ActaObstetGynecolScand 2006;85:912-5.

16. Karadzov-Orlic N, Egic A, Milovanovic Z, Marinkovic M, Damnjanovic-Pazin B, Lukic R, et al. Improved diagnostic accuracy by using secondary ultrasound markers in the firsttrimester screening for trisomies 21, 18 and 13 and Turner syndrome. PrenatDiagn 2012;32:638-43.

This is an open access article distributed under the terms of the Creative Commons Attribution-NonCommercial-ShareAlike 3.0 License, which allows others to remix, tweak, and build upon the work non-commercially, as long as the author is credited and the new creations are licensed under the identical terms

This article was originally published in a special
issue, "Biomedical Research in Healthcare Setting"
Indian J Pharm Sci 2020:82(3)Spl issue5;77-82

